\title{
Una discusión recuperada: candiles musulmanes de disco impreso
}

\author{
Juan Zozaya *
}

Larga y fecunda amistad me une con quien es ahora motivo de cálido homenaje por la comunidad científica de quienes nos dedicamos al mundo de al-Andalus. Inolvidable la generosidad de Guillermo cuando yo era apenas un aspirante a entrar en el Cuerpo de Archiveros, Bibliotecarios y Arqueólogos y él, sin casi conocerme, no dudó en ayudarme "desde fuera". Desde entonces surgió la amistad, la "empatía" no sólo personal sino profesional. Los dos trabajamos el islam andalusí, los dos arquitectura y cerámica, los dos metales, los dos luchamos juntos para que el término científico "andalusi", que hoy parece tan natural, tan obvio, se impusiera, hacia los setenta iniciales, sobre los "hispano-árabes" y los "luso-árabes" y de paso se redujeran las susceptibilidades de investigadores que pudieran ver el mundo islámico peninsular y balear como una afirmación "centralista" o imperialista.

Los tiempos pasaron, la investigación sobre cerámica continuó y en su momento se plantearon dudas sobre la cronología de un determinado género de candiles: el que hoy presento aquí. El homenajeado sosteniendo (como quien suscribe en su momento también lo hizo) que el candil de disco plano impreso era un modelo de transición de la Baja Romanidad al mundo islámico inicial, lo cual parecía formalmente tan obvio.

Tal hipótesis sostenía cuando escribí la síntesis sobre cerámica andalusí que se me encar- gó para lo que después resultaría ser el primer Coloquio Internacional de Cerámica Medieval Mediterránea y así se puede observar si se lee atentamente. Efectivamente: entre el tiempo de redacción (1976-77) y el de su publicación hice un viaje para recoger material, ineludible, a Córdoba para incluirlo en mi Tesis Doctoral (ZOZAYA, 1990). Sumando unos elementos con otros lo primero que llamó mi atención fue la cantidad de los allí existentes. En segundo lugar la amabilidad y generosa observación de Alejandro Marcos y de Ana María Vicens (a la sazón era ésta Directora del Museo Arqueológico Provincial cordobés) sobre cómo este tipo de candil aparecía siempre en relación con contextos almohades fue de interés, y finalmente la presencia de esritura nasjí asociada con este género de candiles, lo cual, evidentemente, impedía que se pudiera adscribirles una fecha en torno al cambio politico, económico y social surgido de la invasión musulmana.

Consecuencia de ello fue rectificar mis opiniones sobre la cronología de estas piezas y la posterior discusión con la persona objeto de este homenaje, hasta tiempos recientes. Al final de mi ponencia del Coloquio de Valbona incluía una addenda et corrigenda en la cual rectificaba ya mi opinión sobre la cronología, igual que lo hice de manera ya más sustanciosa en mi Tesis Doctoral. Guillermo Rosselló estuvo entre los miembros del Tribunal que la juzgaron, $y$ a este respecto sostuve con él una disputatio pública, como conviene en esas ocasiones, al respecto.

* Museo Arqueológico Nacional 
Pienso que este retorno a la cuestión, humorístico homenaje a quien tan merecidamente lo recibe, y que estoy seguro que comprenderá (y sonreirá malévolamente al respecto con una cierta sabia xoca mediterránea) sirve para plantear cuestiones $y$, posiblemente, resolver otras.

Veamos en primer lugar cuál es el inventario de las piezas en cuestión. Previamente hay que hacer una observacion al respecto: los números son los que corresponden a mi Catálogo, dentro del cual se conoce como Género I 00 (siguiendo un "numerus currens"), y dentro de la clasificación de Córdoba como sub-género " $X$ ", dentro del cual se han podidio distinguir 6 sub-divisiones. Hay que observar que prácticamente todas y cada una de ellas son piezas únicas, y sólo se han podido apreciar repeticiones decorativas en algún caso, que se indica llegado el momento.

Veamos el material:

\section{N I00a GÉNERO: Córdoba ESPECIE: "X-I"}

Lugar de procedencia del prototipo: Córdoba

Lugar de depósito: IVDJ

$N^{0} I N V^{\circ}:$--

Descripción: Género a molde y mano, con intrusiones de mica y cuarzo, pasta de color rojizo. El embudo es de orificio, el asa anular, con depósito alto y tronco invertido con piquera de entronque suave con piquea de bañera, con tres facetas. Su técnica decorativa es, aparte del molde, el vedrío. Tiene una decoración de tipo abstracto-geométrico, con una estrella de nudo de ocho, con un embudo de orificio en el centro del mismo.

(I) Dimensiones: Long:: 10,7 cms. Alto: 4,I 57 cms. cuerpo: 6,2 $58 \mathrm{cms}$ y j boca: $2 \mathrm{cms}$. La altura de cuerpo es de 4,1 cms y la longitud de piquera es de $5,5 \mathrm{cms}$.

\section{Datación: S. XIII. Almohades}

Depósito buzando a parte anterior. Decoración a molde, geométrica en parte superior, a partir de lazo de ocho. El fondo con octalfa, con nudo de la vida en el centro y puntos diversos y círculo en espacios entre puntas de la estrella. Vidriado melado integral.

Variantes:

(2) MAP Córdoba. 23.821, proc. Córdoba con piquera y asa rotas. Depósito con parte superior horizontal. Disco superior con orla y tema de dos llaves del Paraíso, lámpara de mezquita a la izquierda y dos palmetas a la derecha. Orificio en parte posterior del disco, junto al entronque del asa. Topes y resalte en lugar de reflector. Disco inferior de orla y canal. Incisiones verticales en cuerpo arrancando de parte superior que acaban a medio cuerpo. Vidriado verde.

(3) MAP Córdoba 3.608, s/p, depósito inclinado en parte superior hacia adelante, con acanaladura en parte superior, con dos llaves del Paraíso y puntos, orificio en parte anterior. Vidriado verde claro.

(4) MA Córdoba, s/n, s/p. Asa rota. Disco con orificio en la parte anterior, próximo a la barrera que separa el disco de la piquera. El disco, con orla floreada, con inscripción en cúfico florido "al-Mulk", con botella encima del "mim" y lámpara sobre el remate del "kaf", sugiriendo el "'alif" y el "lam" las "Llaves del Paraíso". Depósito con incisiones paralelas formando triángulos bajo cubierta. El fondo con orla y acanaladura que va del disco hacia la piquera. Vidriado verde.

(5) MAP Córdoba 2.026, depósito algo inclinado hacia adelante, con disco rehundido. Asa rota que permite ver que fue anular. Orificio en parte anterior, próximo a la piquera. Decoración a molde con dos "Llaves del Paraíso" orladas. Vidriado amarillo.

(6) MAP Córdoba 527, con disco inclinado hacia atrás. Asa anular rota. Orificio adelantado y barrera ante la piquera, con dos topes laterales. Tema decorativo epigráfico en cúfico, "al-Yumn" (la Felicidad) con puntos diacríticos y "sukun". "Arbol de la Vida" sobre el "nun", quizá sustituyendo al punto del mismo, todo ello orlado. Parte inferior mol- 
durada en orla con acanaladura central que se extiende hacia la piquera. Vidriado verde.

(7) MAP Córdoba 528, s/p. Asa anular rota. Parte superior con barrera ante piquera, con 2 topes laterales. Orificio central. Orla con inscripción en relieve en cúfico de transición "al-Yumn", interrumpida en la parte del asa por la misma. Disco central rehundido con flor eptapétala. El fondo, con otra, octopétala en dos orlas concéntricas. Vidriado verde.

(8) MAP Córdoba 12.745 , s/p. variante del prototipo, con orificio central. Vidriado verde excepto en fondo y partes del depósito.

(9) MAP Córdoba MA/MV 202, proc. de la mezquita de Madinat al-Zahra' (PAVON, 1966), con asa rota, disco rehundido, orificio en la parte anterior, lindando con la barrera que separa el cuerpo de la piquera. Orla liriforme arrancando de dos topes laterales próximos a la piquera. Gacela a derecha con cuello vuelto. A su derecha, lámpara de mezquita. Parte inferior impresa con orla vegetal y cuatro círculos en disposición vagamente romboidal, con acanaladura que sale hacia la piquera, con trazos diagonales en la misma y sus bordes. Sin vidriar.

\section{№ I00b GÉNERO: Córdoba ESPECIE: "X-2"}

Lugar de procedencia del prototipo: Sevilla.

Lugar de depósito: MAH Sevilla

$\mathrm{N}^{\circ} \mathrm{INV}^{\circ} .: 6.608$.

Descripción: Molde y mano con intrusiones: vegetales, mica y cuarzo; color: blanco, con embudo de orificio El asa es anular, con deposito alto, tronco invertido. La piquera es de entronque suave en forma de bañera y de tres facetas.

Técnica decorativa: a molde.

Decoración de tipo zoomorfa abstracta y epigráfica

Dimensiones: Long.: > I 1,8 . Alto: 3,6;

f cuerpo: 6,7; f boca: I

Altura de cuerpo:3,6 Long. de piquera: 5,8

Datación: S. XIII. Almohades.
Variantes:

( I) Depósito con tambor tronco-cónico invertido regular, molduras en parte superior del mismo (uniendo con disco) y debajo de la misma otra menor. Disco levemente rehundido, con barrera entre disco y piquera con dos topes laterales. Orificio en parte delantera, próximo a la barrera, en eje central.

Disco con dos molduras periféricas. En centro, en cúfico florido " 'afiya" con diacríticos. Pequeño círculo a la izquierda del remate superior de la "ta' marbuta". En la parte inferior, rodeada por moldura, flor octopétala con círculos en la zona exterior de cada pétalo. Hacia la piquera tres círculos alineados, acanaladura en piquera, en cuyo arranque hay un círculo mayor y dos menores alineados en acanaladura. La piquera con incisiones en metopas triangulares, alternando con círculos. (FERNÁNDEZ-CHICARRO, |950-|95I).

(2) MAP Huelva s/n, comprada a anticuario sevillano, proc. Córdoba. Asa anular, disco con moldura circular, sin orificio. Decoración en disco superior de dos gacelas enfrentadas con cuellos enlazados y vueltos. Círculos a ambos lados de los cuellos (cuatro). Parte inferior con flor octopétala levógira a molde, con puntos en los extremos de los pétalos entre tres molduras circulares. Punto en el eje central y acanaladura estrecha en el mismo, en la parte inferior de la piquera.

(3) MAN 80/68/16, s/p, posiblemente cordobesa, con características morfológicas similares al prototipo, con orificio avanzado en el eje central. Decoración con inscripción en cúfico florido "al-Yumn", con diacríticos. Remates de letras en ápices. Roleos a ambos lados de la inscripción en bandas verticales. En parte inferior, a molde entre dos molduras anulares flor nonapétala. Acanaladura a piquera que sale del fondo, con un punto grande y tres pequeños transversales, en su arranque, Diseños incisos laterales de la piquera, bajo cubierta, formando metopas triangulares adosadas y contrapuestas. Vidriado verde. 
(4) MAP Córdoba I I.834 proc. de Córdoba. Asa anular rota. Sin vidriar, pasta roja. Disco rehundido, con orificio en parte anterior, centrado a eje longitudinal. Orla a modo de láurea en derredor del disco, decorado con caballo pasante a derecha. Cuatro puntos a izquierda, sobre la grupa. A derecha, con palmeta. En el fondo entre dos molduras que se abren a la piquera y a la acanaludura, flor con trece pétalos, radiales, el central próximo a la piquera mayor y más ancho claramente diferenciado. Engobe amarillento.

(5) MAP Córdoba 2.867, Córdoba. Asa anular rota, depósito de planta levemente ovoide, con disco rehundido y topes en unión con la piquera. Diseño interior de concha convergiendo el despiece al centro de la pieza. Dos orificios en el eje transversal de la pieza. En la parte inferior, a molde, flor nonapétala rodeada por canalillo que se abre hacia la piquera, que está rota. En los lados del cuerpo, incisiones verticales bajo cubierta. Vedrío verde.

(6) MAP Córdoba I I.505. Asa anular y piquera rotas. Disco rehundido con orificio en eje longitudinal de la pieza, en zona anterior, próxima a la barrera entre depósito y piquera, con dos topes. Orla laurea-da e interior decorado con lámpara de mezquita saliendo (Corán XXIV,35) de vid, con roleos esquemáticos a cada lado. En paredes incisiones verticales bajo cubierta y en el fondo estrella de veintidós pétalos con moldura liriforme en derredor, que se abre hacia la piquera, sin acanaladura.

(7) MAP Córdoba 12.999, con asa anular y piquera rotas. Disco en láurea, rehundido, con orificio en eje longitudinal, en parte anterior, próximo a la barrera con dos topes laterales que separa al depósito de la piquera. Decoración de orla laureada en borde, con diseño alargado que rodea el orificio en su parte superior, sugiriendo el agujero de una cerradura visto de frente. A su izquierda una lámpara de mezquita (v. pieza anterior) y un recipiente tipo jarro (ipara agua?) como referencias al Paraíso.
En paredes tres molduras, las dos superiores con incisiones bajo cubierta haciendo un diseño de "opus spicatum" (¿o láurea?), y banda inferior con contario en relieve. Debajo, bien hechas, incisiones anchas bajo cubierta. En el fondo "Llave del Paraíso", con moldura orlando que se abre hacia la piquera.

\section{N 100c GENERO: Córdoba ESPECIE: "X-3"}

Lugar de procedencia del prototipo: Sevilla Lugar de depósito: MAH Sevilla $N^{0} I N^{0}: 2.858$

Descripción: Molde y mano, intrusiones: vegetales y cuarzo; color: blanco; embudo con orificio; asa: anular; deposito tronco invertido; piquera de entronque suave con planta de bañera de tres facetas.

Técnica decorativa: molde.

Temas decorativos: Decoración de tipo zoomorfa y abstracta

Dimensiones: Long.: $>8,9$. Alto: 2,7,

f cuerpo: 6,4 , fboca: 0,9

Altura de cuerpo:2,7 Long. de piquera: $>1,2$

Datación: S. XIII, Almohade.

Variantes:

( I) Gran moldura en parte superior. Base cóncava. orificio en parte anterior con barrera de entrelazo entre el depósito y la piquera, que está rota. Disco rehundido entre moldura, con leona y cachorro pasantes a izquierda. En paredes gallonado con metopas mayores y menores. En fondo gallonado continuación del parietal, que remata en arquillos de medio punto, con bocel, media caña y bocel que encierran una flor nonapétala con círculos en los extremos y con núcleo central de siete pequeños círculos aglutinados en torno a uno menor. El bocel exterior se abre hacia la piquera formando acanaladura. Decoración de rayas verticales y metopas triangulares incisas bajo cubierta en lados de piquera. Vidriado verde. 
(2) MAH Sevilla, similar a la anterior en tamaño, con planta de depósito ovoide. Asa anular y piquera rotas. orificio próximo al centro, desviado y barrera en cuña entre el cuerpo y la piquera. Orla de perlas en relieve en torno al disco, levemente rehundido con decoración de incisiones en ángulo recto distribuidas con sus vértices en torno a un centro, como si fuera un tema del Paraíso. Paredes con incisiones diagonales bajo cubierta. Fondo plano. Vidriado marrón.

(3) MNAHM Granada, Nº 2.835, procede de Córdoba por compra a anticuario. Asa anular y piquera rotas. Disco muy levemente rehundido, con el orificio avanzado para dejar lugar a la decoración, de manera que se abre a la piquera. En orla con contario caballo pasante a izquierda, con el cuerpo relleno con puntos. Crines anudadas y sobre el cuello tres puntos dispuestos triangularmente (¿flor de loto simbólica?). Topes a ambos lados de la apertura a piquera. Las paredes tienen una banda anular en la parte superior y la inferior excavada de manera que forma nichos que se reflejan en planta sobre el fondo. Éste no es circular sino que tiende a ser más bien "flamígero" en planta, disposición que sigue la orla con incisiones diagonales, formando un sogueado sobre bocel, que encierra una flor dextrógira eptapétala, con círculos en seis de los pétalos. Acanaladura hacia la piquera. En esta se aprecia un sistema de decoración incisa de metopas con distribución interna de triángulos hechos mediante incisiones en bandas de eje vertical. Pasta blanca.

(4) IVDJ, s/n, s/p, aunque posiblemente Córdoba, con asa anular y piquera completa en planta de bañera. Disco levemente rehundido con orla de bocel-media caña-bocel y decorado con gacela pasante a izquierda, cuya pata trasera derecha rompe el contario que la rodea. La cabeza, al frente, obliga a desplazar el orificio de aprovisionamiento a la izquierda. Barrera entre depósito y piquera. Aquel tiene dos bandas anulares, una menor y otra mayor, de arriba a abajo, que ocupan la mitad superior. La inferior con gallones que se reflejan en la planta de la base, que es plana, con una media caña que aísla la zona central, con flor decapétala con corola circular. Del arranque de la piquera aparece una acanaladura en la parte inferior. A cada lado incisiones verticales bajo cubierta. Vidriado verde.

(5) MNAHM, s/n, procedente de las excavaciones de la Alcazaba de Mérida, pasta de color ocre, intrusiones finas de mica y quizá caliza. Disco superior con aguamanil de tipo persa, orientado hacia el portador, con pie alto, con pitorro rematado en cabeza de caballo, con banda central de aros contiguos sobre el ecuador de su cuerpo, que es claramente globular, el paso del cuerpo al gollete tiene moldura y la misma decoración de anillos.

Mediante ellos se hace una decoración de flor, a la izquierda. Cuatro anillos orlan la base. Dos se encuentran encima del orificio de repostado derecho, y dos, dispuestos verticalmente, en el espacio entre el cuerpo y el asa. Otro orificio de repostado se encuentra a la izquierda, sobre el eje medial de la pieza.

El cuerpo corresponde al modelo general descrito en este sub-tipo. Dos topes y una barrera separan el cuerpo de la piquera por la parte superior. El cuerpo está moldeado en sus paredes, con molduras verticales y aristas, y el fondo está también realizado a molde, con una estrella central de nueve pétalos, con conjuntos de tres círculos formando triángulo en el ápice de cada uno. Todo ello parte de un círculo central. La parte exterior se delimita por dos molduras circulares, que enmarcan una acanaladura. La piquera tiene canal central inferior, que remata en lo que queda, abriéndose, pero no se puede definir más sobre la misma al estar rota su punta. Los lados tienen incisiones laterales verticales y diagonales, con puntilleado triangular siguiendo la parte inferior del borde superior de la piquera. El asa es anular, muy mal desarrollada. Aunque obedece al tipo general 6 no deja de ser dudosa su adscripción a Córdoba debido a lo imperfecto de su ejecución. 
(6) I frag, MNAHRM s/n, con pasta ocre e intrusiones muy finas, de mica y posiblemente de caliza. Vidriado verde con disco superior en el cual se aprecian restos de inscripción en caracteres cúficos mal desarrollados, una de cuyas palabras puede corresponder a "Muhammad" ("Mahoma"), con tipo de letra un tanto extraño. Parece tener orla de círculos en relieve.

El exterior es también con molduras, a juzgar por lo que queda, debiendo ser anular el asa.

(7) Candil (Col. Ibrahim, Madrid,) Torno y mano. Intrusiones de mica y cuarzo. Pasta color rojizo. Embudo anular, simple. Asa anular. Depósito alto. Piquera de entronque suave, destruída. Vedrío integral . Decoración de tipo epigráfica y figurativa (barco). Dimensiones: Long.: Alto: $2,7 \mathrm{cms}$. $\varnothing$ cuerpo: $6,3 \mathrm{cms}$. $\varnothing$ boca: destruida. Vidriado verde que ocupa todo el cuerpo. Presenta en el disco superior el relieve de una nao de tipo genovés navegando a derecha, con viento en popa. Se aprecia proa vuelta, castillete grande de proa y icebadera? inflada. No se aprecia el palo, ya que por ahí el candil está roto. En la cebadera se aprecia la inscripción, en relieve "Bismi". Debajo, a punzón, tres círculos en distribución triangular con el vértice a derecha. En el casco, desde el arranque del castillete de proa, y ocupando casi todo el ancho del mismo la inscripción en "cursiva-cúfica" "Bahr ibn 'Aly $a($ mir?)" El 'ayn está roto en su parte superior y el alfi maqsura de 'Aly es vuelto. La popa permite apreciar algo del timón de espadilla. La rotura del candil no permite apreciar la vela mayor, que posiblemente debió estar henchida y llevar la continuación con "Allah".

El cuerpo presenta moldura sencilla corrida, de $0,8 \mathrm{cms}$. de ancho. El fondo es cóncavo, está destruído y no permite apreciar más que una doble y tenue acanaladura en derredor del solero (?), para señalar el comienzo del mismo. Se ignora si éste continuó hacia la piquera o no, cuyo arranque ha desaparecido. El barco es de un tipo conocido por otras piezas (BERTI, PASTOR \& ROSSELLÓ, 1993) y asociable al comercio del Mediterráneo como tipo italiano (LANDSTRÖM, 1978; ZOZAYA, 1994).

\section{NNo I00d GENERO: Córdoba ESPECIE: "X-4"}

Lugar de procedencia del prototipo: Córdoba Lugar de depósito: MAP Córdoba $N^{\circ}$ INV $^{\circ}: 24.635$

Descripción: molde y mano; intrusiones de cuarzo; color: rojizo; embudo de orificio; asa: anular con depósito: alto y tronco invertido y piquera de entronque suave.

Técnica decorativa a molde.

Temas decorativos de tipo epigráfico.

Dimensiones: Long.: >9,4; alto: 2, I; f cuerpo: 5,8;

f boca: 1,2; altura de cuerpo: 2, I;

long. de piquera: $>4$

Datación: S. XIII. Almohades.

Variantes:

(I) Asa anular y piquera rotos. Disco central rehundido en concavidad. Barrera entre el depósito y la piquera, con dos topes laterales. orificio en parte posterior, próximo al entronque del asa, centrado con eje longitudinal.

En la parte superior orla laureada sobre bocel, incisa. Disco impreso con leyenda en cúfico, a dos renglones: "barak(a)/alyumn", sin puntos diacríticos. En "baraka" parece faltar la "ta' marbuta". La escritura tiene un surco central, y sólo el "ya'" presenta un remate floral. La pared es lisa y el fondo tiene un bocel que se abre hacia la piquera, insinuando la acanaladura.

(2) MAP Córdoba 6.898. Asa anular y piquera rotas. Disco plano, sin orificio. Orla de bocel con barrera pequeña entre depósito y piquera, con dos pequeños topes. Jinete pasante a izquierda, con arbol esquemático. El caballo con cola atada, según indican las incisiones torsas en la misma. Sobre la grupa motivo cruciforme con puntos en los vanos. 
Pared lisa. Fondo con bocel e incisiones en la parte interior, en despiece diagonal que se abre hacia una acanaladura que se desarrolla bajo la piquera. Vedrío verde.

(3) MAP 17/56, proc. de Córdoba, con asa anular y piquera rotas. Disco cóncavo, con bocel como orla. orificio algo central, grande, fuera de los ejes de la pieza, algo retrasado y a la izquierda. En torno diseño floral de cuatro vértices y cuatro lóbulos. En el lado opuesto diseños de cuñas poco claros. Barrera con un tope a un lado. Presumiblemente tuvo otro al lado opuesto, separando el cuerpo de la piquera. Vidriado verde oliva.

(4) MAP Córdoba 8.025, proc. de Córdoba. Asa anular rota, con piquera en bañera. Barrera con incisiones torsas y dos topes entre depósito y piquera. Orla laureada en exterior, con media caña y orificio en parte anterior, cerca de los topes, bastante alineado con el eje longitudinal. Decoración impresa de lámpara de mezquita con olivos esquemáticos a los lados. Depósito y piquera sin decoración. Fondo con bocel y media caña. El fondo, plano, con incisiones torsas que señalan el interior de la media caña, abriéndose al canal de la piquera. Vidriado verde oliva.

(5) MAP Córdoba 23.822, con asa anular y piquera rotos. Orla de bocel y media caña. Orificio descentrado a la izquierda. Barrera con topes entre depósito y piquera. Decoración impresa de jinete a derecha, con espada en diestra, el caballo reculando, como se deduce de la postura de la cola del caballo.

El jinete con escudo en el brazo izquierdo, fechable iconográficamente hacia el 1220 (Grube, 1977) y diestra levantada, la pierna doblada, hacia las ancas del caballo, como si estuviera espoleándolo. En realidad el jinete, además de espolear al caballo probablemente está representado montando "a la jineta", manera característicamente almohade. El caballo lleva brida a modo de ronzal, y va controlado por la izquierda del jinete, pues pasa del hocico por detrás del cuerpo. Encima de la grupa se aprecia un roleo ¿símbolo de victoria? ¿de vida eterna? Vedrío verde. Pared lisa fondo como el de la pieza anterior.

(6) MAP Córdoba s/n, de Córdoba, con asa anular rota y piquera de bañera. Disco cóncavo, con orificio central. Barrera con dos topes entre depósito y piquera. Decoración impresa de octalfa. Cuerpo y piquera lisas. Fondo similar al anterior. Pasta roja.

(7) MAP Huelva s/n, procedente de Córdoba, según el anticuario vendedor. Asa anular y piquera rotas, pero es permisible pensar que la piquera sea de bañera. orificio en la parte posterior, alineado con eje longitudinal. Barrera con dos topes entre cuerpo y piquera. Disco cóncavo con diseño impreso, orlado de láurea, con pseudo-inscripción simétrica en cúfico florido, con diseño cruciforme rematado en "punta de lanza". Vidriado verde.

Hay una variante, decorativamente muy próxima, en la ex-colección Blanco, en Córdoba, hoy en la Colección de la Academia de BB.AA. y NN.LL. de Córdoba, con número de inventario L-I. Completa la parte baja del diseño de la cara superior con pequeños círculos. El orificio del embudo no toca el arranque del asa y en cambio afecta a la parte inferior de la decoración. El lanceolado va en relieve en el borde. El roleo que va al exterior de los elementos verticales laterales es, en cambio, curvo y grácil.

(8) MNAHM Granada 2.836, procedente de Córdoba según nota de compra. Anillo anular y piquera rotos. Aquél, mal hecho, remataba en el disco. Orificio central, piquera recedida al depósito, con barrera y dos topes entre el depósito y la piquera. Bocel en derredor que delimita la parte entrante de la piquera.

Más adentro zona plana con inscripción impresa en nasjí "al-Yumn" que según Fernández (comunicación verbal) es del siglo 
XIII. La inscripción tiene ápices, en algunos de los "'alif" y "lam" reminiscentes del cúfico. La orla está separada por un bocel del motivo central, tambien impreso, de una flor eptapétala, con perlas entre los extremos de los pétalos. El cuerpo tiene banda anular e incisiones verticales, y el fondo es con dos boceles y una flor octopétala. Pasta rosácea.

(9) MAN 80/68/17, proc. de Córdoba. Asa anular. Piquera rota. Disco con moldura con láurea. Barrera con dos topes laterales entre depósito y piquera. Uno de los topes con diseño floral inciso. Orificio irregular en la parte anterior del depósito, centrado con el eje longitudinal. Disco algo rehundido con decoración impresa de gacela pasante a derecha y un candelabro sobre trípode, con pebetero encendido, en la izquierda. Pared y fondo lisos. Vidriado verde. Además hay I SMA Ceuta, s/n, Procede de Ceuta, asa anular y piquera rota. Orificio centrado, disco con tema floral impreso, fondo con "sello de Salomón". Vidriada. (Fernández, 1977; 1988). Otro en Laboratorio de Arte, U. de Sevilla con inscripción (?) cúfica. Vidriado azul.

\section{№ 100e GÉNERO: Córdoba ESPECIE: "X-5"}

Lugar de procedencia del prototipo: Córdoba Lugar de depósito: MAP Córdoba $\mathrm{N}^{\circ} \mathrm{INV}^{\circ} .:$ : $\mid 1.504$

Descripción: Hecho a molde y mano, con intrusiones: de cuarzo: el color de la pasta es rojizo. El embudo es de orificio, el asa es anular, el depósito es alto y tronco invertido; la pique$\mathrm{ra}$ es de entronque suave en forma de bañera y tres facetas.

Técnica decorativa a molde con temas decorativos de tipo vegetal y abstracta.

Dimensiones: Long.: $>8,4 \mathrm{cms}$; alto: $3,2 \mathrm{cms} ; \varnothing$ cuerpo: 6,8 cms; $\varnothing$ boca: $1,2 \mathrm{cms}$; altura de cuerpo:3,2 cms; long. de piquera: $>2,5 \mathrm{cms}$.

Datación: S. XIII. Almohades.
Variantes:

Asa anular y piquera rotas. Disco plano, orificio próximo a límite entre depósito y piquera. Orla de dovelaje. Disco impreso con arco de mihrab, formando hornacina en cuyo interior hay una lámpara de mezquita. De los salmeres salen sendas palmetas digitadas, estando muy bien hecha la izquierda. El arco es apuntado, y queda encuadrado con los topes que hay en la zona entre el cuerpo y la piquera. El orificio está orlado por un bocel.

El cuerpo está orlado por decoración estampillada de círculos, puntos, flores de loto, cuadrados con punto central e hilera vertical, próxima a la piquera, de ovas. El fondo tiene media caña con el interior con incisiones que se abre hacia la piquera, acanaladura. El interior está sin vidriar. El resto de la pieza tiene vedrío verde oscuro.

\section{№ I00f GÉNERO: Córdoba ESPECIE: "X-6"}

Lugar de procedencia del prototipo: Córdoba Lugar de depósito: MAP Córdoba $\mathrm{N}^{\circ}$ INV$^{\circ} .: 5.493$

Descripción: Pieza a molde y mano con intrusiones de mica y cuarzo. El color es amarillo; el embudo es de orificio, el asa es anular, el depósito es bajo; la piquera es de entronque suave $y$ de tipo de bañera.

Sólo tiene vedrío. La decoración es sólo de molduras en la tija central.

Dimensiones: Long.: $>7,3 \mathrm{cms}$. Alto: 6,5

cms f cuerpo: 7,3 cms f boca: 6, I

Altura de cuerpo: $2,1 \mathrm{cms}$.

Datación: S. XIII, almohade.

Variantes:

Variante con cazoleta abierta, indicando piquera. Protuberancia central, rematada en pináculo hueco en su interior. Asa anular interior. Depósito abierto. Vidriado verde excepto parte inferior de depósito y asa. 


\section{CONCLUSIONES}

Sólo quiero hacer referencia a varios elementos aquí presentes, de los cuales, entre lo visto, sirven para fechar estas piezas, que quizás nos den noticias sobre la data, ciertamente no la del momento transicional a los musulmanes. Posiblemente la extensión de la familia de linternas de disco impreso sea más amplia de lo pensado antes, pero está entre el 1110 y el I228 como fechas tope. Los elementos que dan estas fechas (me inclino más hacia las próximas al I 160-1212) son:

I) uso de la escritura nasjí como elemento decorativo

2) uso dominante de la jaculatoria "al-yumn", poco frecuente aislada en el mundo omeya $y$ frecuente en el almohade.

3) uso de la "llave del paraíso", tema inusado en la decoración omeya.

4) empleo de un "thimaterion" con base similar a los del siglo XII-XIII encontrados en Denia y descritos por Azuar.

5) uso de lámparas de asas, de vidrio evidentemente, características del siglo XII-XIII en Oriente.

6) Uso del tema de la lámpara en el nicho del Mihrab, alusión coránica cuya referencia visual no ocurre en Oriente antes del siglo XII.

7) Uso del escudo señalado en 100-d-5 fechado perfectamente en el 1220 por Grube.

8) El tipo de barco señalado en el barco del candil de la colección Ibrahim, tardío. El nombre del almirante hace dudar si no hay que subir la fecha, pues se sabe que los almorávides tienen un almirante que se llamaba 'Ali, que, por otra parte, es un nombre asaz común dentro de la nomenclatura musulmana.

El escaso paréntesis cronológico se sitúa, pues, entre el I I70-1220 para estas piezas.

Hasta aquí los hechos, aquí mi homenaje (por hoy) a mi amigo Guillermo Rosselló.

\section{BIBLIOGRAFÍA:}

BERTI, G., PASTOR, J. \& ROSSELLO, G. (1993): "Naves andalusíes en cerámicas mallorquinas" en Trabajos del Museo de Mallorca, $5 \mathrm{I}$.

CORÁN (1979): EI Edición preparada por Julio Cortés. Madrid.

FERNÁNDEZ, E. (1977): Cerámica hispano-musulmana de la Sala Arqueológica de Ceuta. Ceuta.

FERNÁNDEZ, E. (1988): Ceuta Medieval. Aportación al estudio de las cerámicas (siglo X-XV). Ceuta.

FERNÁNDEZ, -CHICARRO, C. (1950-1951): "Museo Arqueológico de Sevilla. Adquisiciones" en Memorias de los Museos Arqueológicos Provinciales II - 12., pp. 47 - 60.

GRUBE, E. (1976): Islamic pottery of the Eight to the Fifteenth centuriy in the Keir Collection. Londres.

LANDSTRÖM, B. (1978) Sailing ships in words and pictures from papyrus boats to full riggers. Londres.

PAVÓN, B. (1966) "Memoria de la Excavación de la mezquita de Medinat al-Zahra" en Excavaciones Arqueológicas en España, 50. Madrid.

ZOZAYA, J. (1990): Tipología y cronología de los candiles de piquera en cerámica de Al-Andalus. Tesis Doctoral inédita. Madrid.

ZOZAYA, J. (1994) "Construcción naval e ingeniería portuaria en el mundo antiguo y medieval" en Puertos españoles en la Historia. Madrid, pp. 43 - 59. 


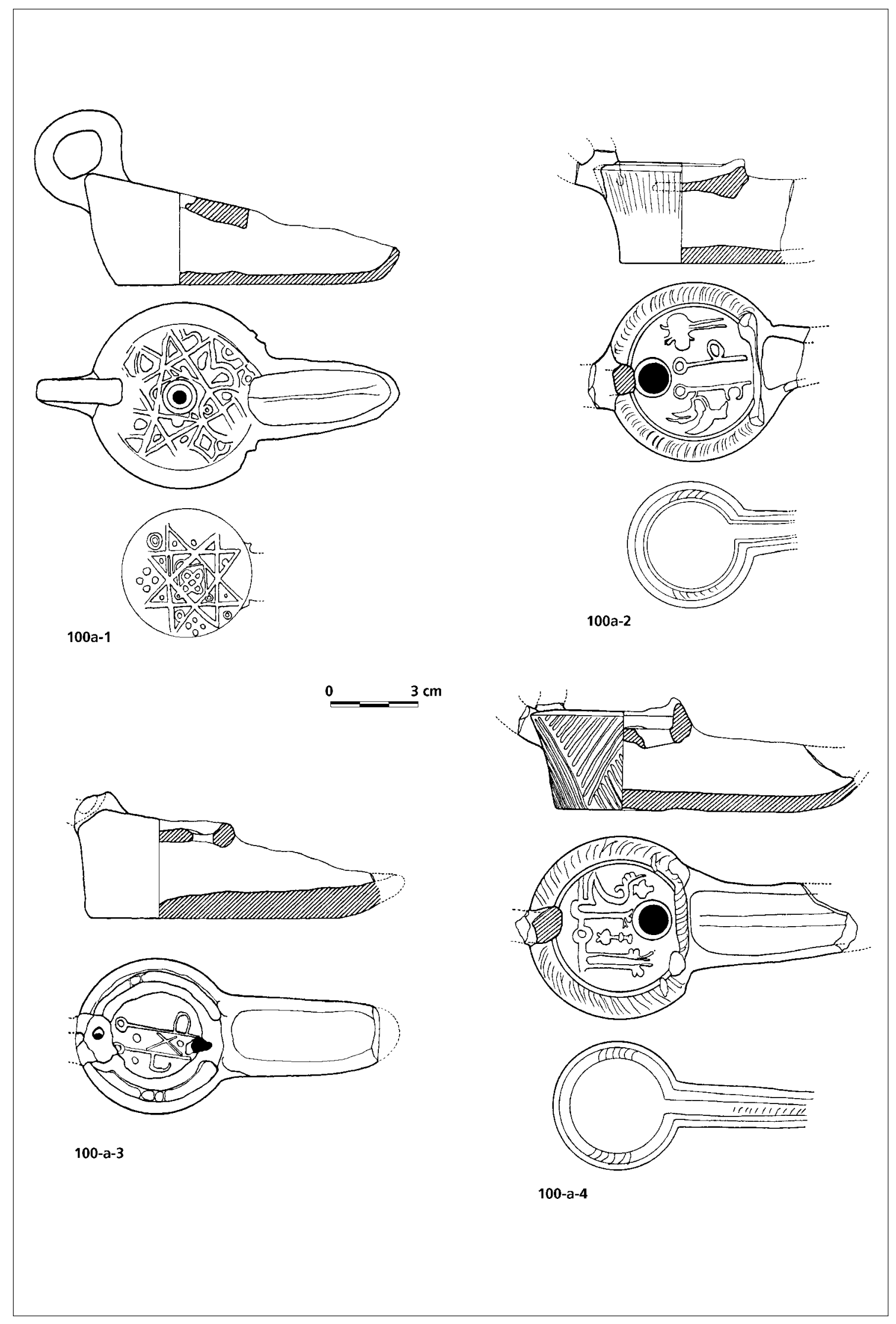




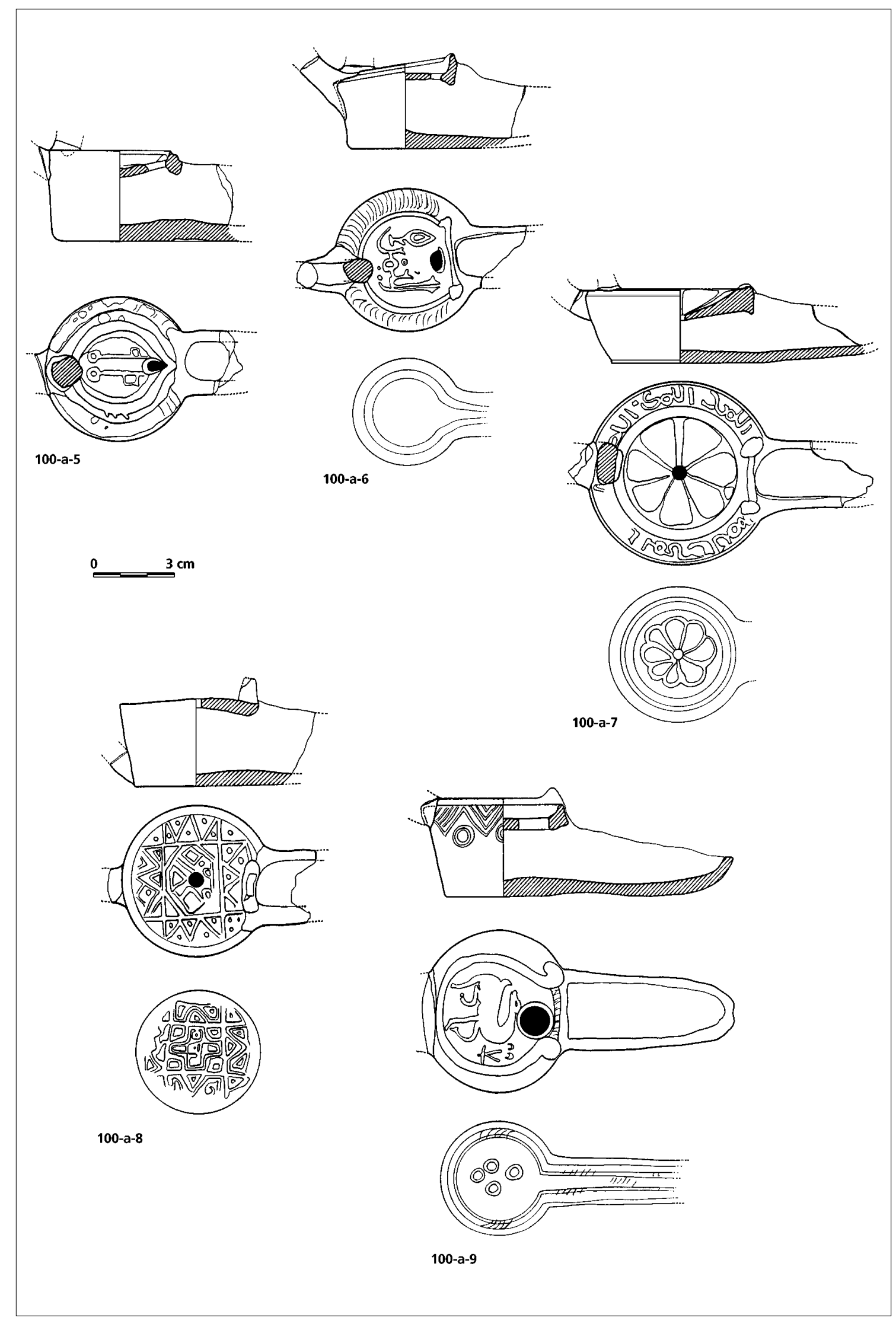




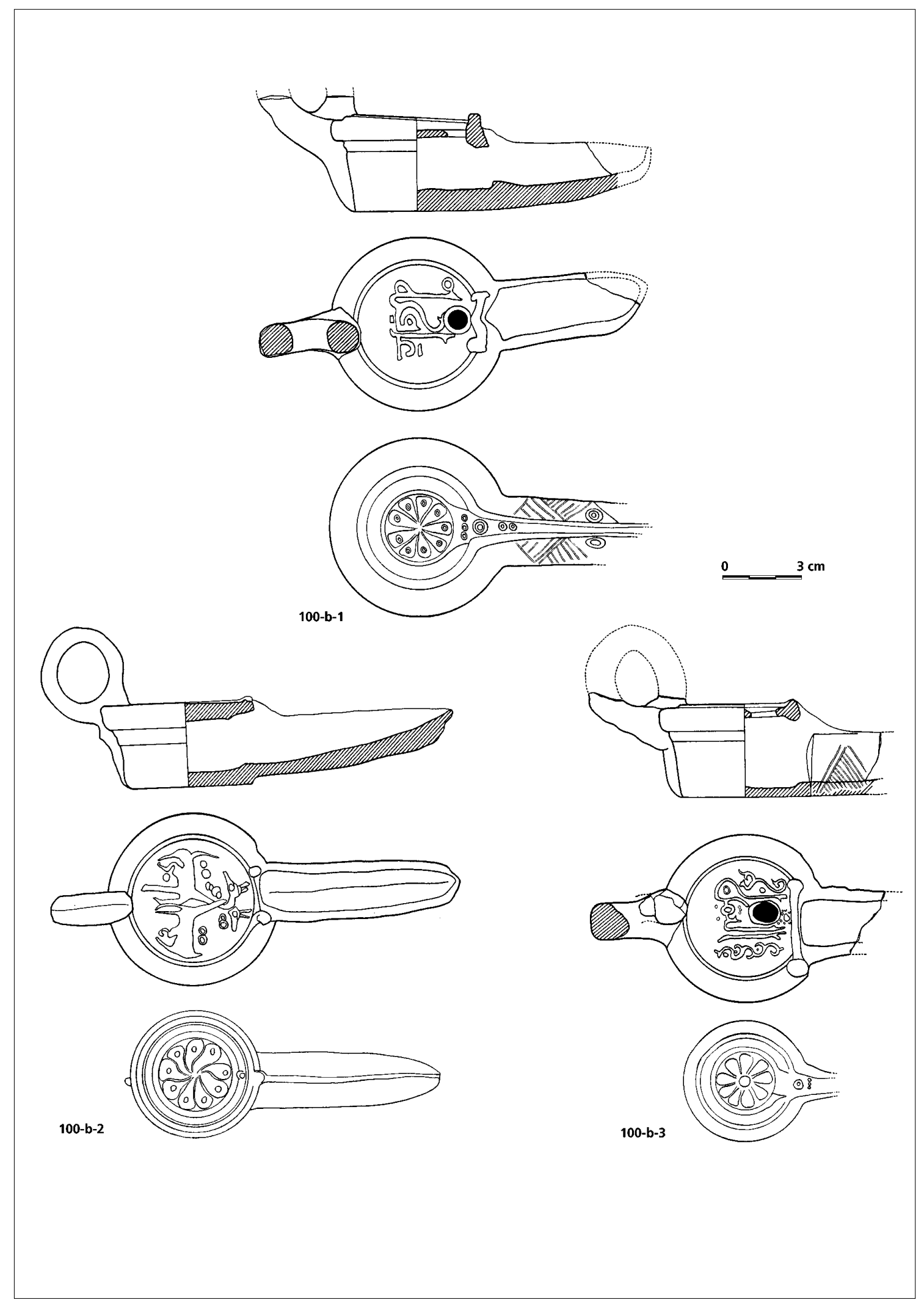




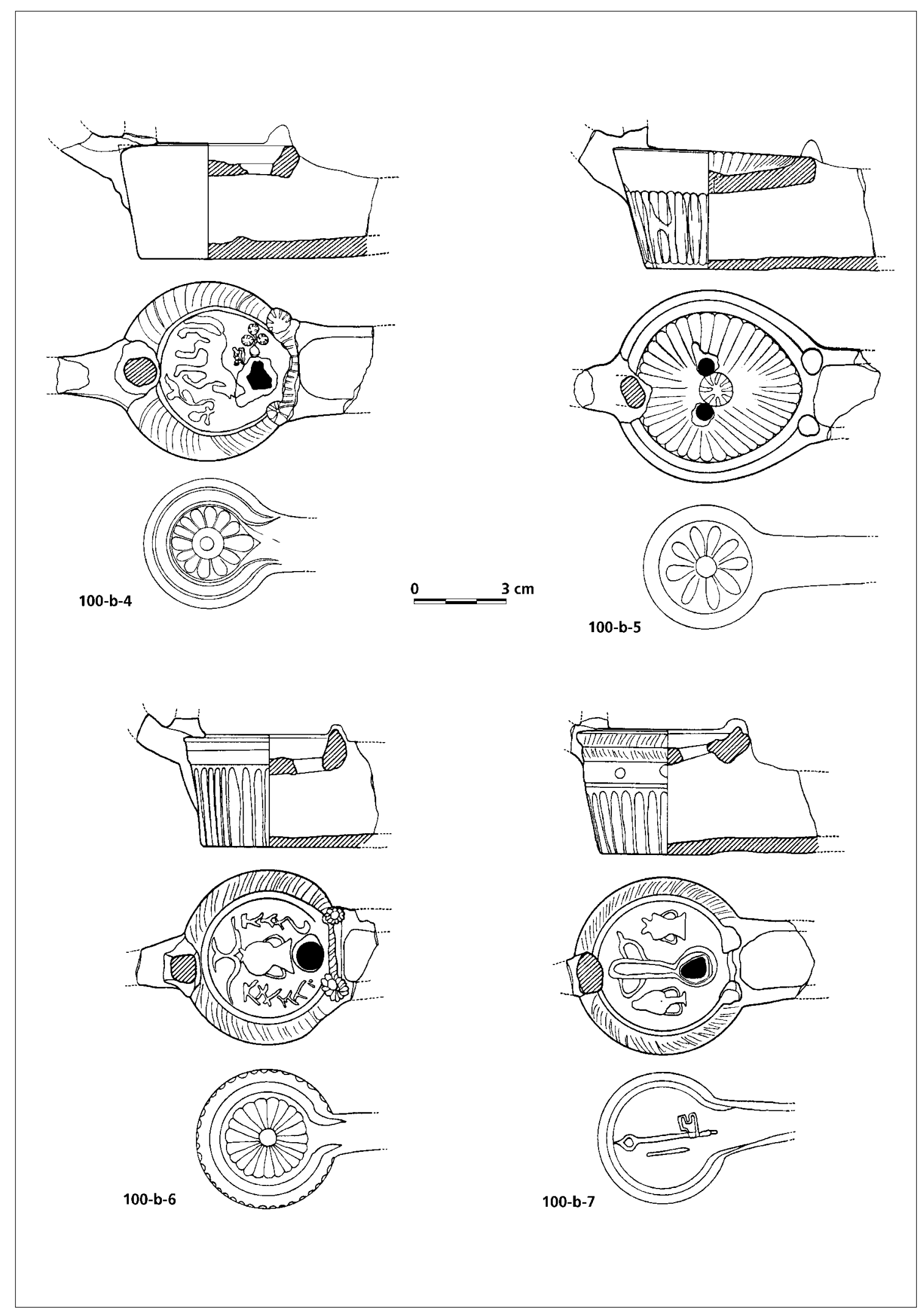



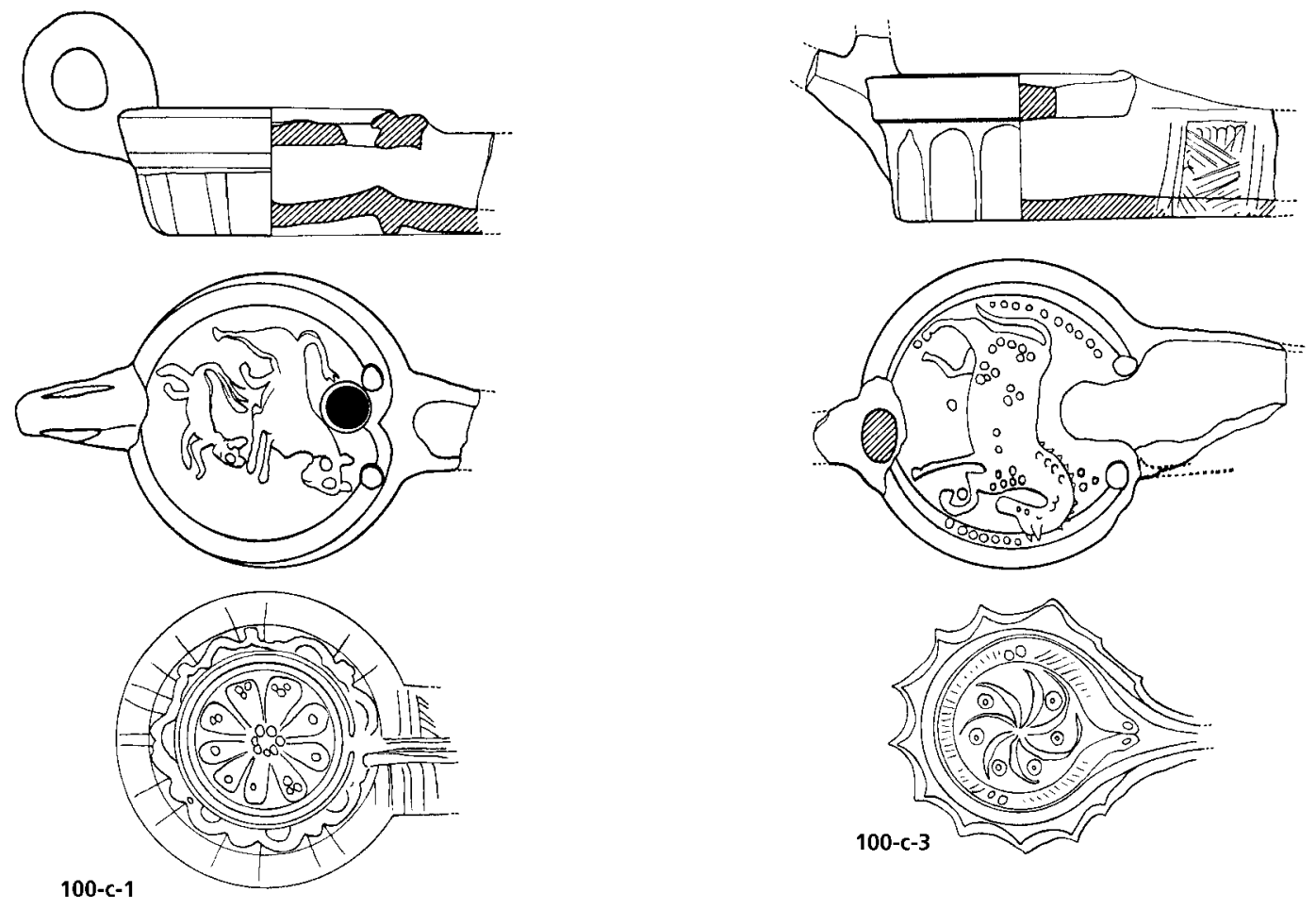

tis
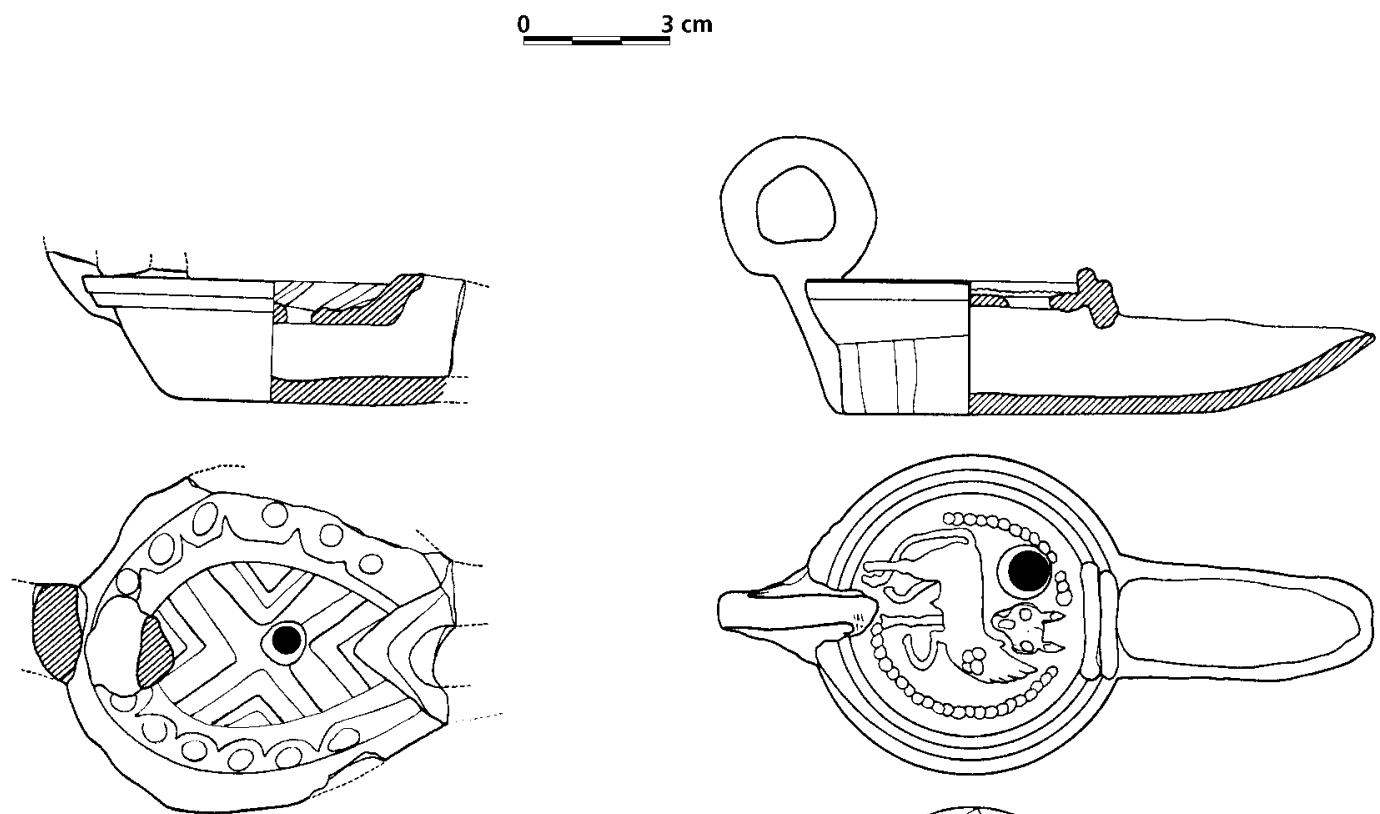

$100-c-2$

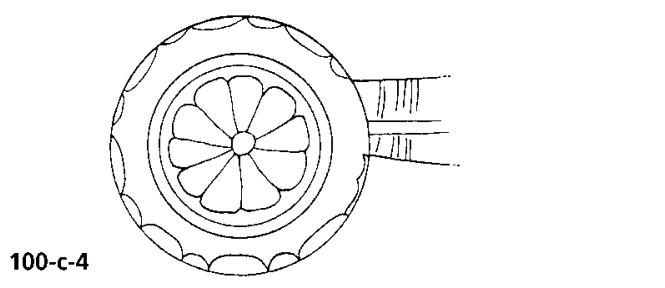




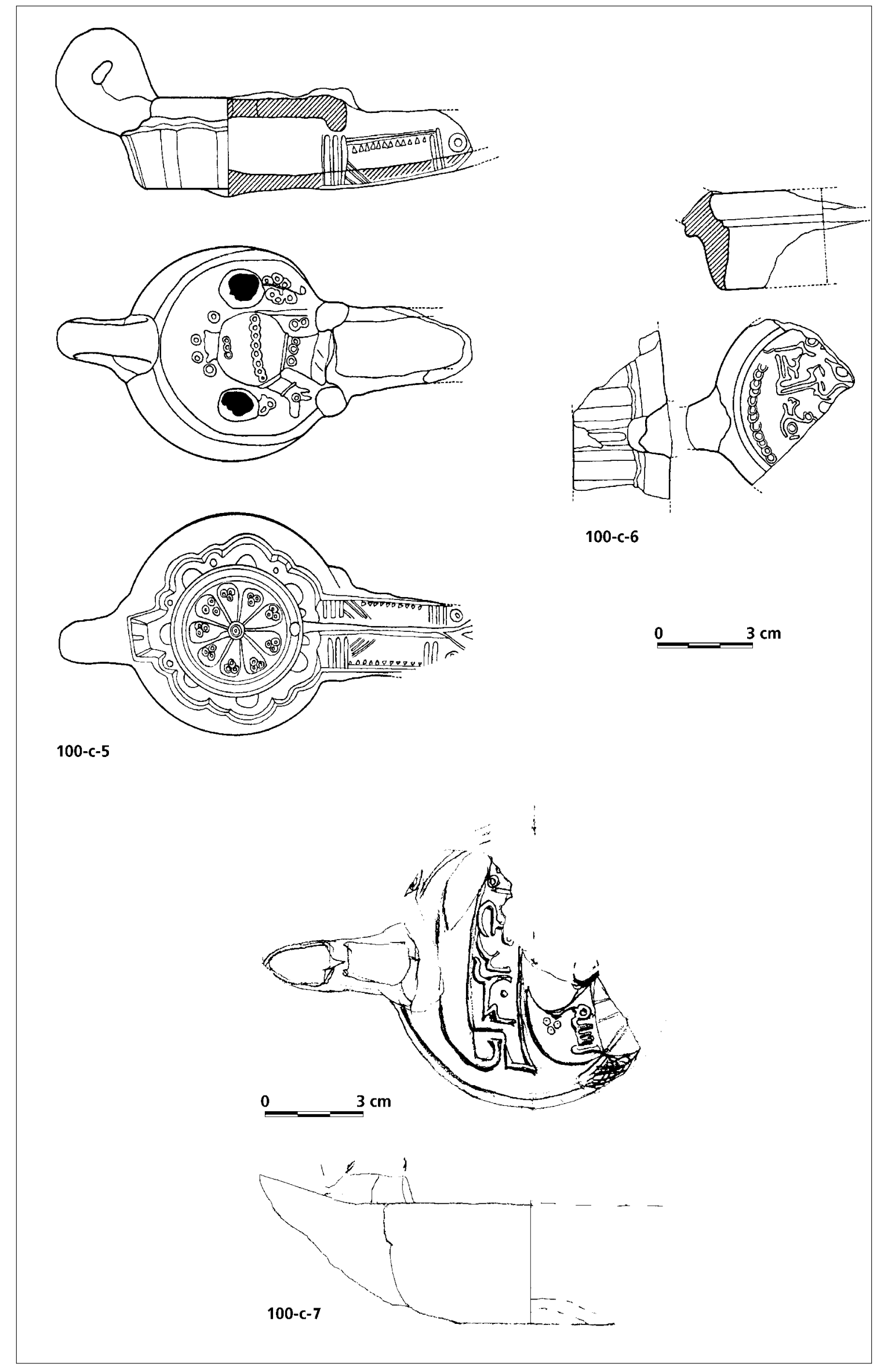




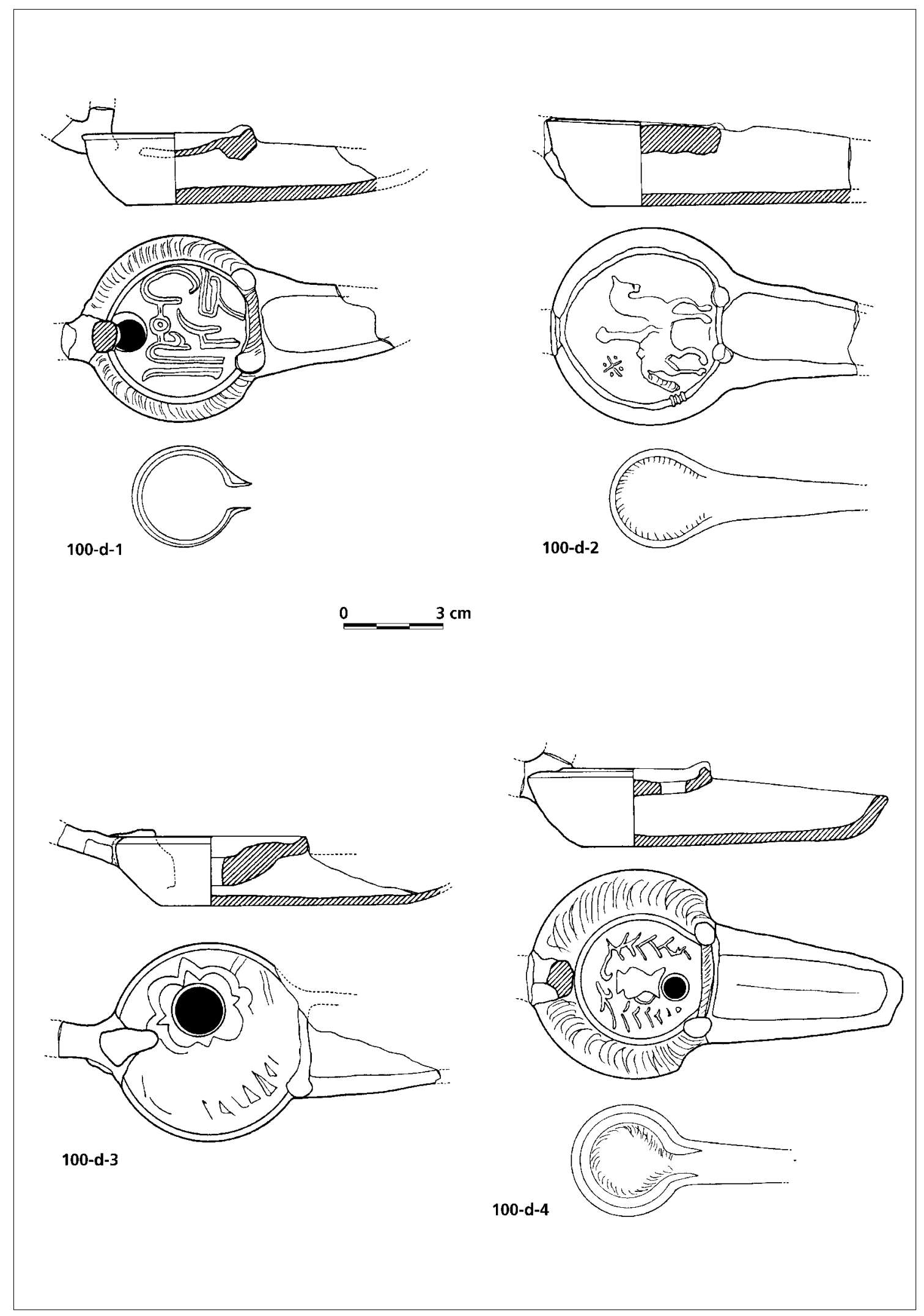




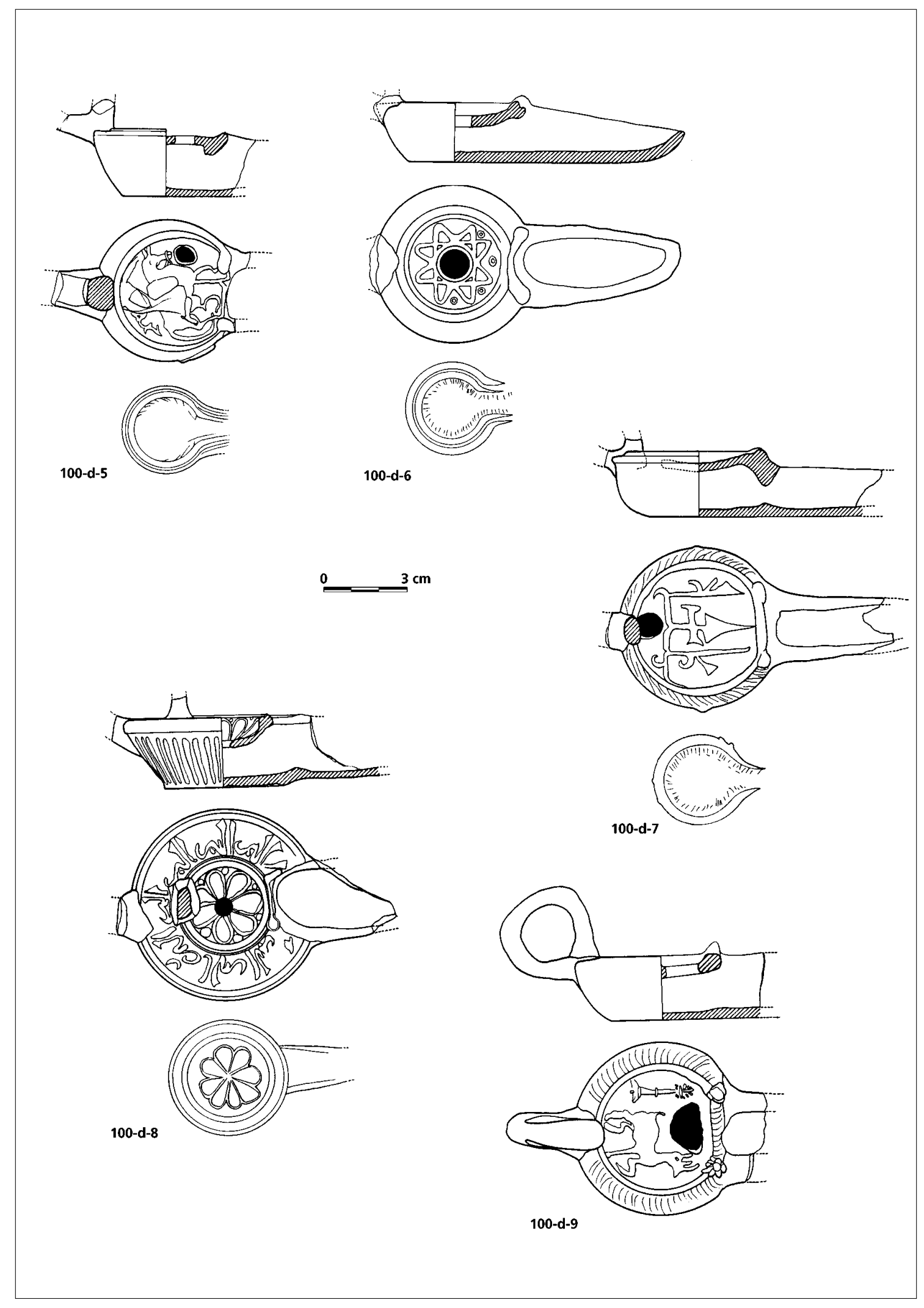




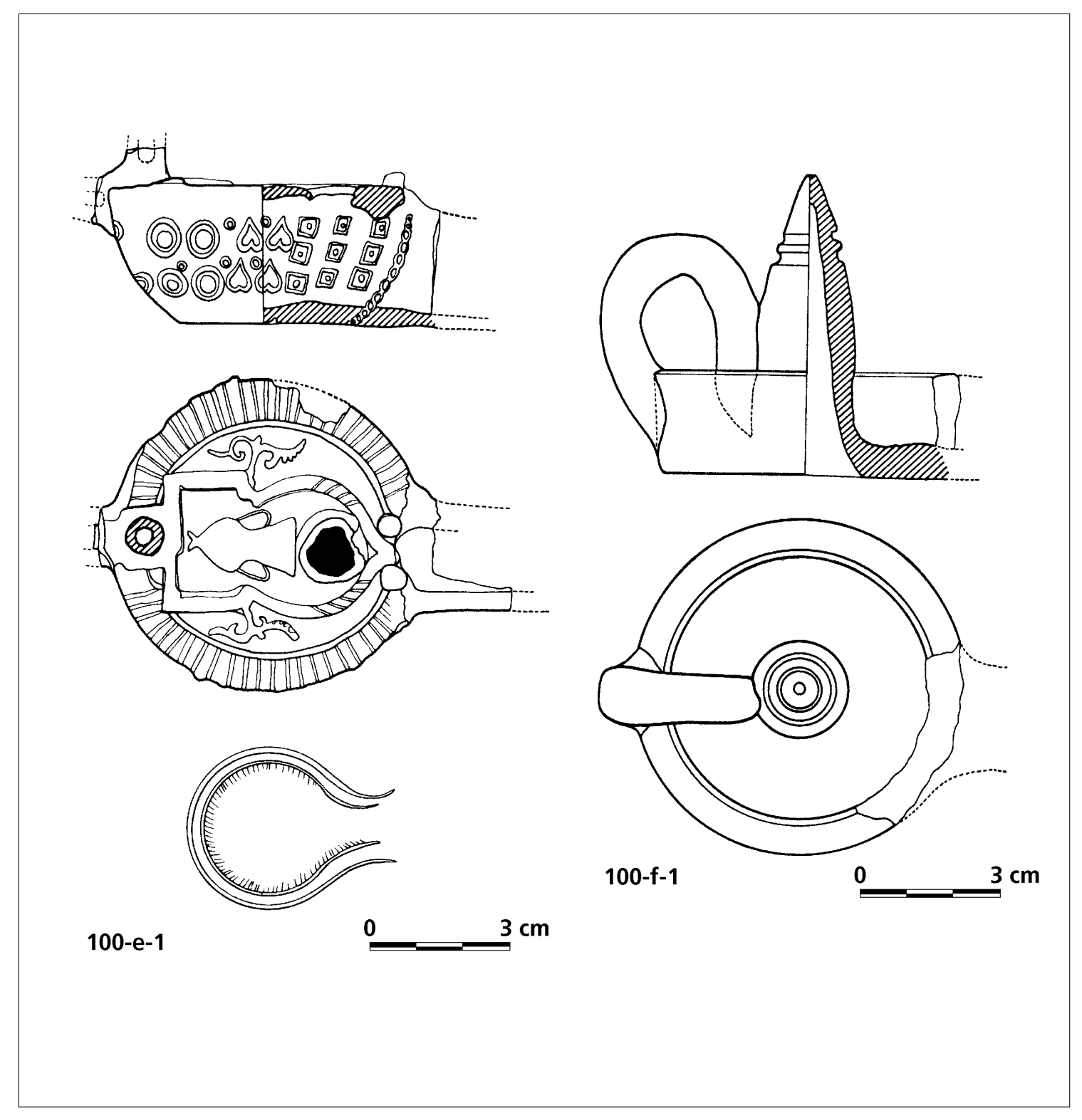

